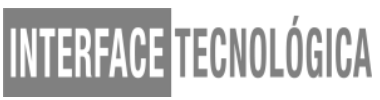

\title{
A IMPORTÂNCIA DA ECONOMIA CIRCULAR PARA O APROVEITAMENTO INTELIGENTE DOS RECURSOS NATURAIS
}

THE IMPORTANCE OF CIRCULAR ECONOMY FOR INTELLIGENT USE OF

NATURAL RESOURCES

\author{
Naiara Bianchi - naiarabianchi44@hotmail.com \\ Universidade de São Paulo (USP) - EESC - São Carlos - São Paulo - Brasil
}

DOI: 10.31510/infa.v17i1.718

\begin{abstract}
RESUMO
Antigamente tinha-se em mente que não era possível se mensurar as maneiras de intervenção ou modificação do meio ambiente, bem como seus possíveis impactos, não tendo assim nenhuma preocupação com as causas ambientais. Mas, atualmente, se possui uma grande conscientização ambiental expressas em legislações, consciência popular e pressões de órgãos internacionais. A ideia principal é eliminar o conceito de lixo, fazendo todo material se manter dentro de um fluxo cíclico, tendo a trajetória dele "do berço ao berço", retransmitindo assim seu valor. Este reaproveitamento inteligente propicia o crescimento econômico, pois este não mais depende apenas de novos recursos, mas da reutilização dos já existentes, permitindo que matérias primas continuem sempre aumentando seu valor. Desse modo, a economia circular se tornou um sistema intencionalmente reparador ou regenerativo, e essa pesquisa bibliográfica explanatória tem por objetivo demostrar os seus benefícios operacionais e estratégicos, assim como o gigantesco potencial de geração de empregos, inovação e crescimento econômico, se mostrando um modelo capaz de não só reduzir a matéria prima, como incrementar as inovações nos processos da produção industrial.
\end{abstract}

Palavras-chave: Economia Circular. Economia Linear. Gestão dos Recursos Naturais

\begin{abstract}
In the past, it was kept in mind that it was not possible to measure the ways of intervention or modification of the environment, as well as their possible impacts, thus having no concern with environmental causes. But, today, there is a great environmental awareness expressed in legislation, popular conscience and pressure from international bodies. The main idea is to eliminate the concept of garbage, making all material remain within a cyclical flow, having its trajectory "from the cradle to the cradle", thus relaying its value. This intelligent reuse provides economic growth, as it no longer depends only on new resources, but on the reuse of existing ones, allowing raw materials to continue to increase their value. Thus, the circular economy has become an intentionally repairing or regenerative system, and this explanatory bibliographic research aims to demonstrate its operational and strategic benefits, as well as the gigantic potential for job creation, innovation and economic growth, proving to be a model capable of not only reducing the raw material, but also increasing innovations in industrial production processes.
\end{abstract}

Keywords: Circular Economy. Linear Economy. Natural Resource Management 


\section{INTRODUÇÃO}

Segundo Araújo (2017), antigamente tinha-se em mente que não era possível se mensurar as maneiras de intervenção ou modificação do meio ambiente, bem como seus possíveis impactos, não tendo assim nenhuma preocupação com as causas ambientais. Mas, atualmente, se possui uma grande conscientização ambiental expressas em legislações, consciência popular e pressões de órgãos internacionais. Os novos projetos sempre estão necessitando de uma avaliação preliminar dos impactos ambientais hoje em dia, pois a sustentabilidade está se tornando cada dia mais importante tanto no meio social quanto ambiental.

Novos conceitos que vão ao encontro das questões de sustentabilidade vêm surgindo como possibilidade de implantação. Para Stahel (2016), a economia circular é um dos conceitos que vem mais se destacando atualmente, pois ela basicamente envolve a transformação de bens no fim de seu ciclo de vida em recursos para outros processos, fechando assim ciclos em ecossistemas industriais e minimizando resíduos, e também sendo capaz de alterar a lógica econômica, pois se substitui a produção por suficiência, reutilizando, reciclando, reparando e remanufaturando.

De acordo com Pereira (2019), a economia circular tem por princípio a constante circulação por meio de cadeias produtivas integradas. Não ocorre mais o descarte, pois o material deixa de ser visto como um resíduo e passa, agora, ser parte de um novo processo. A ideia principal é eliminar o conceito de lixo, fazendo todo material se manter dentro de um fluxo cíclico, tendo a trajetória dele "do berço ao berço", retransmitindo assim seu valor. Este reaproveitamento inteligente propicia o crescimento econômico, pois não mais depende-se apenas de novos recursos, mas da reutilização dos já existentes, permitindo que matérias primas continuem sempre aumentando seu valor. Desse modo, a economia circular se tornou um sistema intencionalmente reparador ou regenerativo, trazendo benefícios operacionais e estratégicos, assim como um gigantesco potencial de geração de empregos, inovação e crescimento econômico. 




\section{FUNDAMENTAÇÃO TEÓRICA}

Em um planeta onde a demanda e a competição por recursos finitos, e as vezes escassos, continuarão a crescer, onde pressão por esses mesmos recursos está causando uma grande degradação ambiental, os países que se esforçam em fazer melhor uso se beneficiam economicamente e ambientalmente. A partir da Revolução Industrial, as economias criaram um padrão de desenvolvimento baseado em um princípio de "extrair-transformar-descartar", sendo assim, um modelo linear baseado na conjectura de que os recursos são abundantes, disponíveis, fáceis e muito acessíveis. (LEITAO, 2015)

De acordo com Mota (2017), o descarte de produtos em aterros significa que toda a sua energia residual foi perdida, pois com a incineração ou reciclagem dos produtos descartados recupera somente uma pequena porção dessa energia, enquanto a reutilização preserva significantemente mais energia. Com o uso de recursos energéticos no modelo de produção linear é tipicamente mais intenso nas áreas superiores da cadeia de suprimentos, por exemplo na extração de materiais para conversão em uso comercial. A perspectiva da economia circular refere-se à uma economia industrial que é restaurativa por intenção, ou seja, que visa a dependência em energias renováveis, em eliminação do uso de químicos tóxicos e erradicação da perda. Existe uma defensa pela necessidade de um modelo de "serviço funcional" no qual os produtores ou vendedores retêm cada vez mais o domínio sobre seus produtos em atuem como provedores de serviço - por meio da venda do uso do produto, e não a venda de um único sentido.

Para Azevedo (2015), o modelo de economia linear foi um modelo resultante da Revolução Industrial que não só expandiu a eficiência da produção, como também propiciou uma exploração das novas tecnologias. A disponibilidade abundante de matérias-primas extraíveis da natureza foi um dos motivos que proporcionaram o crescimento econômico e o desenvolvimento tecnológico. Mas também, essa exploração descontrolada das matériasprimas causou um desequilíbrio ambiental oriundo da produção desenfreada de resíduos industriais que excede a capacidade da natureza de decompô-los. Um dos principais problemas ambientais provocados pela sociedade é o descarte proveniente da exploração do

meio ambiente para ter recursos para produção de bens e consumos. Sendo que, o desequilíbrio ambiental é gerado pelo esgotamento dos recursos que suportam as necessidades 
humanas e, o lixo que é gerado pela produção, é cada vez mais composto por restos de embalagens e produtos industriais, que deixaram de ter finalidade para seus desfrutadores.

\section{PROCEDIMENTOS METODOLÓGICOS}

Este artigo trata-se de uma pesquisa bibliográfica explanatória, sendo elaborada a partir de materiais já publicados, constituído basicamente por artigos de periódicos, livros e materiais publicados na internet, sendo redigida no período de agosto à outubro de 2019. Esta pesquisa bibliográfica tem por objetivo caracterizar um estudo sobre o tema de Economia circular e sua importância no mundo atual, o estudo foi construído com base na procura de artigos que possuíssem estudos realizados de maneira ampla pelos seus autores por meio de bases de dados digitais, tais como a SciELO e CAPES. (MOTA, 2017)

\section{RESULTADOS E DISCUSSÃO}

De acordo com Pereira (2019), o termo economia circular está presente na literatura em diferentes áreas do conhecimento, seu princípio deu-se em 1848, quando R.W. Hofman, $1^{\circ}$ presidente da Royal Society of Chemistry, declarou que em uma fábrica de produtos químicos ideal, não existe nenhum desperdício, mas apenas produtos. Quanto melhor uma fábrica real faz uso de seus resíduos, quanto mais se aproxima de seu ideal, maior é o lucro. Depois deste pensamento, ocorreu a preocupação com os limites do crescimento e a escassez de recursos econômicos, remontam a Malthus e Ricardo, na década de 1960, quando ocorreu a publicação do livro Primavera Silenciosa, isto é, Silent Spring em seu título original, de Rachel Carlson (1962) e, logo após, com Ken Boulding (1966), no ensaio “A economia da terra da nave espacial". Sendo assim, o autor defende que o seu humano necessita encontrar seu lugar em um sistema ecológico cíclico, sendo capaz de reproduzir continuamente formas materiais desde que ocorra a necessidade de uma entra

Segundo Araújo (2017), a economia circular visa inserir o tema na equipe estratégica das empresas, uma vez que esta metodologia é regenerativa e restaurativa, e tem por objetivo mantes os produtos, componentes e materiais em constante nível de utilidade e valor. $\mathrm{O}$ conceito provém do desenvolvimento do pensamento eco industrial, o qual tem como base a 
filosofia "ganho-ganho", que afirma que uma economia saudável também pode ter uma boa saúde ambiental.

Stahel (2016) compara a economia linear com um rio, pois ela tem a capacidade de transformar os recursos naturais em materiais de base e produtos à venda por meio de diversas etapas de valor agregado. No ponto de venda, a propriedade e a responsabilidade por riscos e resíduos passam ao comprador. Ou seja, a economia linear se faz eficientemente capaz de superar a escassez, pois as organizações acabam ganhando muito dinheiro vendendo enormes volumes de suas mercadorias. A Figura 1 ilustra bem o comparativo entre os dois sistemas, em que podemos visualizar que na economia linear não é apresentado o fator da reciclagem, como na economia circular, fazendo com que esta feche assim ciclos em ecossistemas industriais e consequentemente ocorra a minimização dos resíduos, e também se faz capaz de alterar a lógica econômica, pois se substitui a produção por suficiência, reutilizando, reciclando, reparando e remanufaturando.

\section{Figura 1 - Economia linear e a Economia circular}
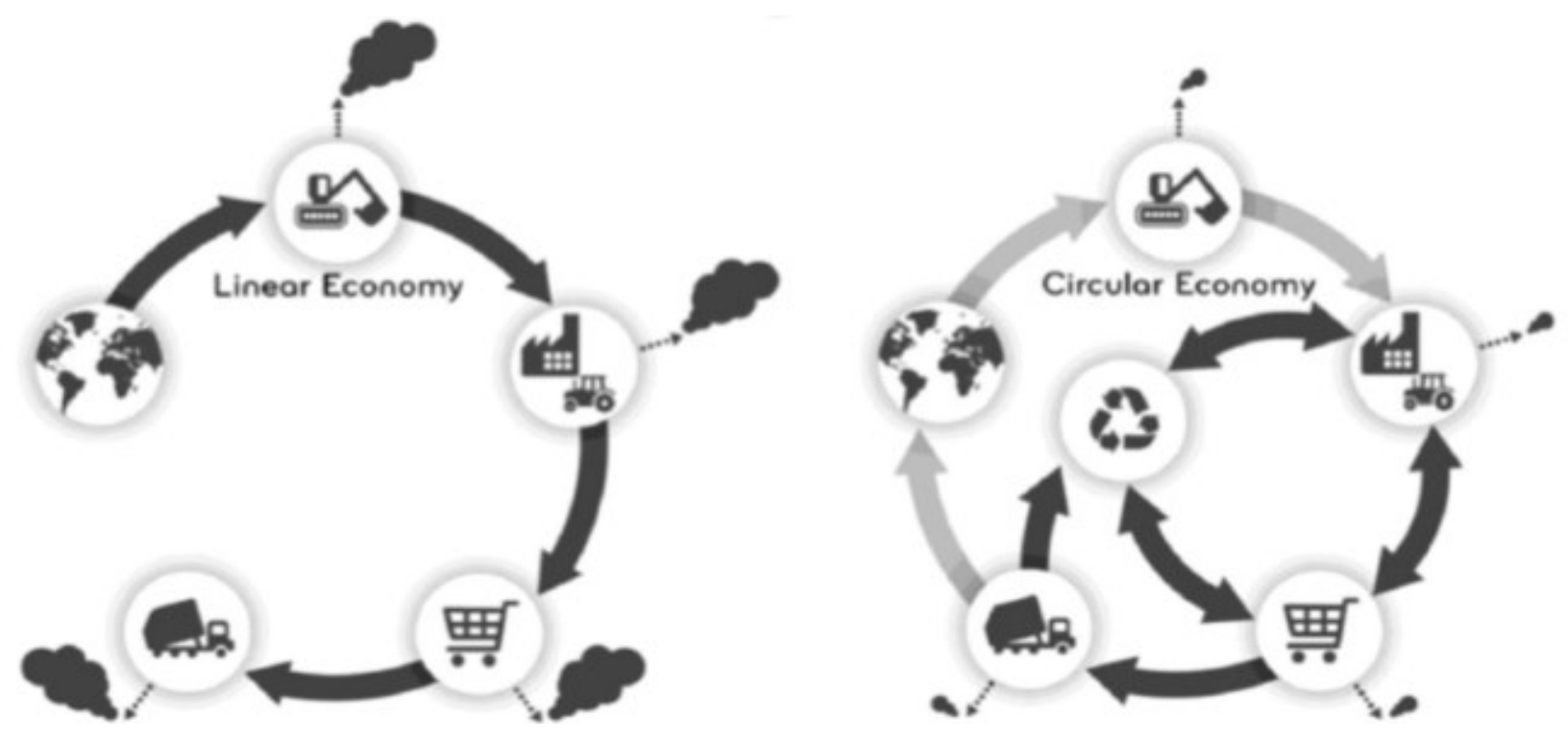

Fonte: Araújo (2017)

Portanto, a economia circular consiste, basicamente, em um ciclo de desenvolvimento contínuo que visa preservar e aprimorar o capital natural, otimizando a produção de recursos e minimizando riscos sistêmicos administrando estoques finitos e fluxos renováveis, oferecendo 


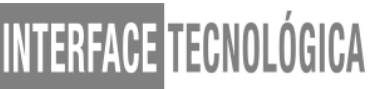

diversos mecanismos de criação de valor dissociados do consumo de recursos finitos. (ARAÚJO, 2017)

\subsection{Economia espiral}

Economia espiral é uma variação relacionada ao conceito de economia circular. Seu princípio fundamental é que é possível aprender como o mundo natural e aplicar esses conceitos nas empresas e na economia. Os subprodutos de uma empresa não só formam o subproduto de outra empresa, mas também podem se tornar grandes oportunidades de desdobramento em diferentes escalas, como a frequência de Fibonacci, que diz que um grupo delicado de pessoas podem projetar e aproveitar diferentes tipos de interações e efeitos em rede, como pode ser observado na Figura 2 abaixo. (HARWOOD, 2017)

\section{Figura 2 - Economia espiral}

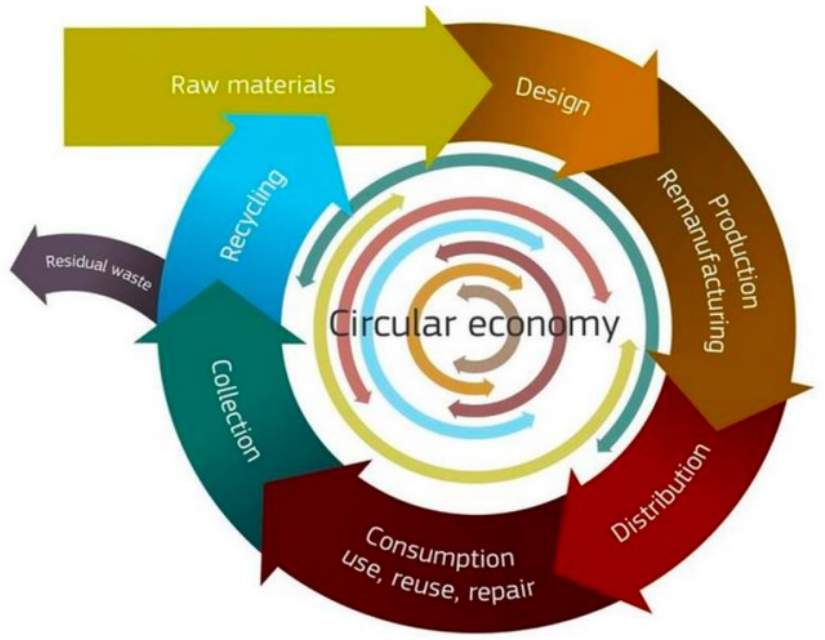

Fonte: Harwood (2017)

\subsection{Do berço ao berço (Cradle to Cradle)}

Para Araújo (2017), a definição de "Do berço ao berço" tem como base fundamental os sistemas naturais e os organismos vivos presentes em nosso planeta, que possuem como seu alimento o "desperdício" de outros organismos. Este ciclo biológico foi modelo para se desenvolver o princípio básico da chamada economia circular. Os resíduos que inicialmente sofrem o descarte são desmontados após o seu uso e são novamente utilizados para gerar 
novos produtos. Essa técnica consiste, basicamente, em reaproveitar os resíduos principais como alimento, além de conseguir usufruir de energias renováveis e da diversidade, sempre levando como princípio base a inteligência dos sistemas naturais presentes em nosso planeta.

O design do berço ao berço tem por objetivo eliminar o conceito de resíduo, pois ele visa a elaboração de novos produtos e materiais que são seguros para a saúde humana e para o meio ambiente, podendo ser reutilizados constantemente, para o melhor uso das energias renováveis, da água, gerando, assim, ecossistemas mais saudáveis e reduzindo significativamente os impactos ambientais. (ARAÚJO, 2017)

Segundo Stahel (2016), a gestão de resíduos convencional tem como base fundamental a minimização dos custos de recolha e/ou sua eliminação, já na economia circular, o principal objetivo é maximizar o valor de cada ponto do ciclo de vida de um produto, sendo assim, fazse de suma importância o investimento em pesquisas e inovações em todos os níveis, tanto no social, quanto no tecnológico e no empresarial. Desenvolver e projetar produtos para a reutilização precisa se tornar uma realidade.

O Cradle to Cradle apresenta às organizações a oportunidade de oferecer seus produtos não só apenas para venda, mas também disponíveis para uso. Após o uso do produto, os materiais são retirados como parte de um sistema de reprocessamento e, assim, permanecem em circulação. As organizações podem tornar-se menos dependentes das flutuações de preços nos mercados de matérias-primas. (ARAÚJO, 2017)

\subsection{Logística reversa}

De acordo com Pereira (2019), a logística reversa, também chamada de reversível ou inversa, é a área da logística que estuda, basicamente o fluxo de produtos, embalagens ou materiais, desde o ponto de consumo até o local de origem, ou seja, o ciclo inverso da logística tradicional. Os processos de logística reversa são desenvolvidos há muitos anos, contudo não eram tratados com a devida importância que merecem. Alguns exemplos da logística reversa, podemos citar: o retorno das garrafas (vasilhame), a recolha/coleta de lixos e resíduos recicláveis. A logística reversa possui como sua base a questão que envolve a recuperação dos produtos desde o ponto de consumo, para que retornem até o local de origem ou de decomposição adequada, com o menor risco ambiental possível. 
A logística reversa tem que ser vista como um processo baseado basicamente no planejamento, implementação e controle eficiente do fluxo econômico de matérias-primas, inventário em processo, produtos acabados e informações relacionadas ao ponto de consumo como também ao ponto de origem, com o propósito de recuperar valor ou disposição adequada. De acordo com a Política Nacional de Resíduos Sólidos (estabelecida pela lei 12.305 de 2/08/2010), a logística reversa deve ser definida como um instrumento de desenvolvimento econômico e social caracterizado por um conjunto de ações, procedimentos e meios destinados a viabilizar a coleta e a restituição dos resíduos sólidos ao setor empresarial, para o seus correto reaproveitamento, em todo o ciclo de vida desse produto ou em outros ciclos produtivos, ou, ainda, outra destinação final ambientalmente correta. (PEREIRA, 2019)

Portanto, para Pereira (2019), em suma, a logística reversa tem como objetivos planejar, implementar e controlar de um modo eficiente e eficaz:

- O retorno ou a recuperação de produtos;

- A redução do consumo de matérias-primas;

- A reciclagem, a substituição e a reutilização de materiais;

- A deposição de resíduos;

- A reparação e refabricação de produtos;

Desta maneira, o circuito da cadeia de abastecimento é fechado de uma forma completa, sendo o ciclo logístico completo.

\subsection{Implantação da economia circular}

A implementação em larga escala da economia circular é considerada uma grande mudança do paradigma, em todos seus aspectos, tanto de atividades sociais, quanto de econômicas, pois atualmente apenas se possui um conceito de sustentabilidade quando se refere apenas a coleta seletiva de resíduos, tentativas individuais de reciclagem ou aumento da eficiência energética. (BONCIU, 2014)

Segundo Araújo (2017), a economia circular é uma política de regulamentação, se torna um exemplo quando se aborda os temas referentes ao desenvolvimento sustentável, em especial na China, pois seu governo adotou como base política, a introdução de vários 


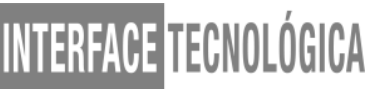

regulamentos para apoiar e consolidar a sua implementação no país. Dentre as ações realizadas, a primeira delas foi a "lei de promoção da produção mais limpa", a qual entrou em vigor em janeiro de 2003. Esta regulamentação foi seguida pela "lei sobre prevenção da poluição e controle de resíduos sólidos" que entrou em vigor em $1^{\circ}$ de abril de 2005 . Em 29 de agosto de 2008, a "lei de promoção da economia circular" foi aprovada na $4^{\text {a }}$ reunião do Comitê Permanente do $11^{\circ}$ Congresso Nacional do Povo da China e entrou em vigor em $1^{\circ}$ de janeiro de 2009. Essa lei promove o desenvolvimento da economia circular, tendo por objetivo, melhorar a eficiência da utilização de recursos, protegendo o seu meio ambiente e promovendo o desenvolvimento sustentável e vigora até os dias atuais.

A União Europeia, por sua vez, também visa a implementação da economia circular, pois, com ela seria possível preservar o valor de seus produtos pelo maior tempo possível e praticamente levar a zero seus desperdícios. Os seus recursos, por sua vez, permaneceram no ciclo econômico até que alcancem um novo uso produtivo, adquirindo mais valor. A Comissão Europeia está ainda em fase de iniciação em relação ao seu processo de implementação, estão desenvolvendo estudos para melhor abordar a questão do desperdício para que assim possam implementar e acompanhar de maneira adequada a economia circular, mas no quadro atual, ainda se torna de suma importância o desenvolvimento de pesquisas para poder convencer as empresas e governos que esse tipo de economia é verdadeiramente viável. (BONCIU, 2014)

Nesta nova percepção, os recursos não representam apenas mais algo adquirido a um custo do meio ambiente e de forma linear, mas também um componente do processo de produção que é esquematizado de forma circular: os recursos são primeiramente obtidos do meio ambiente, mas depois o que seria desperdício torna-se um novo recurso e é reincidido indefinidamente no processo econômico. (BONCIU, 2014)

\subsection{Interfaces entre os conceitos que representam a economia circular}

Segundo Pereira (2019), as interfaces que foram identificadas entre os conceitos descritos no estudo de economia circular podem ser visualizadas na Figura 3. 
Figura 3 - Interface entre os conceitos de economia circular

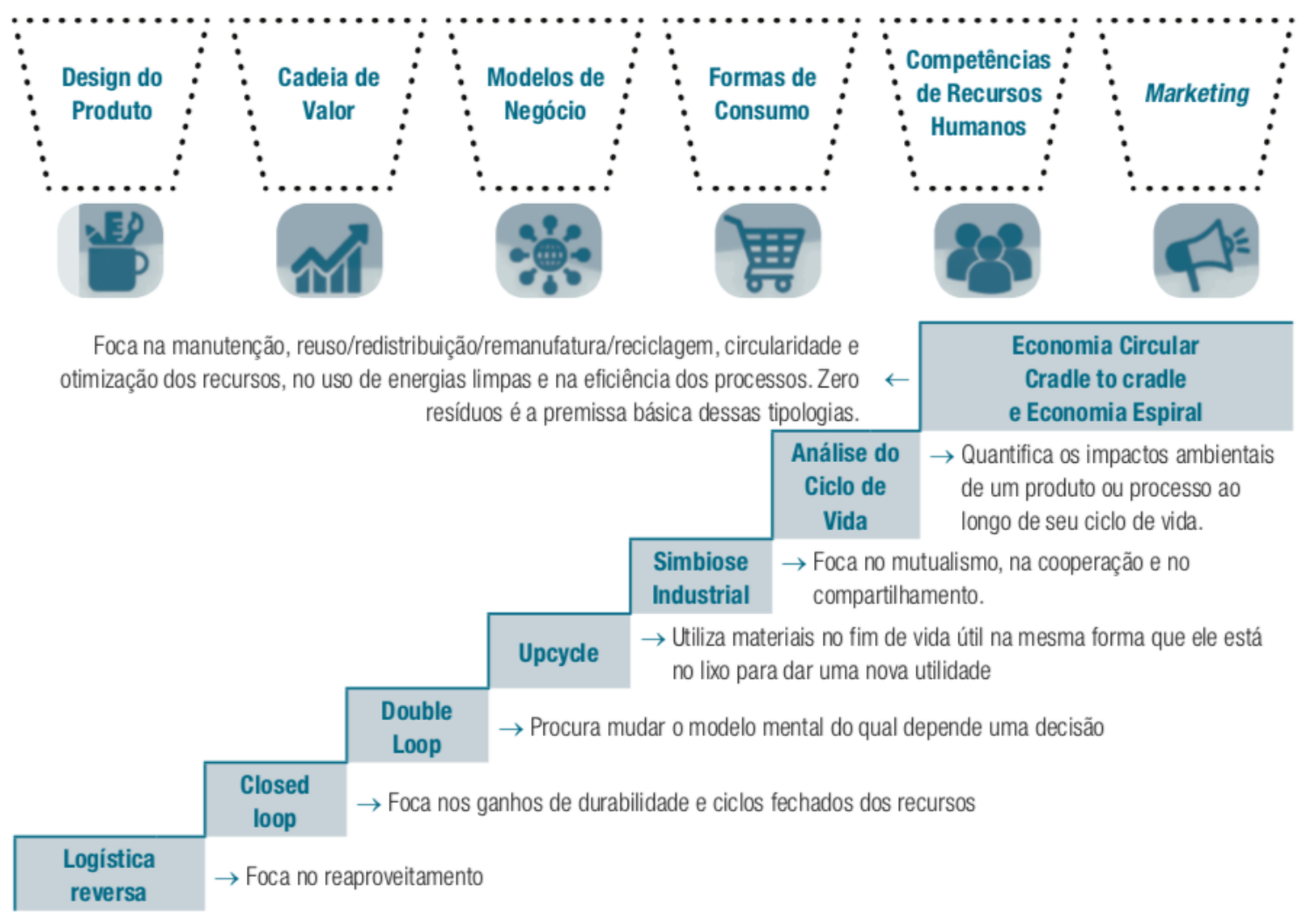

Fonte: Pereira (2019)

Todos os conceitos existentes na Figura 3 podem ser aplicados em toda a cadeia de valor de um produto ou serviço, desde sua criação até sua destinação final. Mas, a complexidade tende a aumentar no decorrer de toda a cadeia produtiva, como também a constante necessidade de inovação que torne viável este desenvolvimento sustentável. Dessa maneira, é possível se criar uma escada evolutiva desses conceitos de produção, tendo como referência a logística reversa (coleta e reaproveitamento dos resíduos), closed loop (preza a circularidade dos recursos), double loop (procura criar alternativas para que os resíduos sejam reintroduzidos na cadeia de produção), upcycle (usa criatividade e inovatividade), simbiose industrial (foca no mutualismo, na cooperação e no compartilhamento), análise do ciclo de vida (quantifica os impactos ambientais associados a um produto ou processo), cradle to cradle (recursos geridos de forma circular), economia espiral e economia circular (circularidade dos recursos). E muitas vezes, perspectivas complementares aplicadas 
juntamente com as atividades industriais podem gerar significativos resultados em relação a sustentabilidade do planeta.

\section{CONSIDERAÇÕES FINAIS}

Diante a importância da economia circular frente às novas tendências do pensamento sustentável as questões ambientais devem ser incorporadas no sistema econômico, visto que é de suma importância investigar como a economia circular se integra com a sustentabilidade, como também suas influências sobre o desenvolvimento econômico-sustentável e as inovações. Perpetuar o desenvolvimento da economia adjunto com o meio ambiente sempre é o maior dos desafios para a nova geração, mas mesmo que ainda se possua diversas barreiras e restrições sobre este novo segmento da economia, aos poucos têm que ir desenvolvendo a mentalidade da economia circular, sendo um modelo capaz de não só reduzir a matéria prima, como incrementar as inovações nos processos da produção industrial.

\section{REFERÊNCIAS}

ARAÚJO, Thaís Duek de. ECONOMIA CIRCULAR: BREVE PANORAMA DA PRODUÇÃO CIENTÍFICA ENTRE 2007 E 2017.. In: ENGEMA USP, 19., 2017, Mato Grosso do Sul. Anais . Mato Grosso do Sul: Usp, 2017. p. 2 - 17. Disponível em: $<$ http://engemausp.submissao.com.br/19/anais/arquivos/417.pdf > . Acesso em: 10 set. 2019.

AZEVEDO, Juliana Laboissière. A Economia circular aplicada no Brasil: Uma análise a partir dos instrumentos legais existentes para a logística reversa. In: CONGRESSO NACIONAL DE EXCELENCIA EM GESTAO, 6., 2015, Rio de Janeiro.

BONCIU, F. The European economy: From a linear to a circular economy. Romanian Journal of European Affairs. v. 14, p. 78-91, 2014.

Harwood, R. (2017). Towards a spiral economy. 2017. Disponível em: < https://www.100open.com/towards-a-spiral-economy/>. Acesso em: 10 set. 2019.

Lei Federal No 12.305, de 02 de agosto de 2010. Institui a Política Nacional de Resíduos Sólidos e dá outras providências. Disponível em: $<$ http://www.planalto.gov.br/ccivil_03/_ato2007-2010/2010/lei/112305.htm>. Acesso em: 18 maio 2020. 
LEITÃO, Alexandra. A Economia circular: uma nova filosofia de gestão para o séc. XXI.. Portuguese Journal of Finance, Management and Accounting. 1 (2), 149-171. Disponível em http://u3isjournal.isvouga.pt/index.php/PJFMA>. Acesso em: 10 set. 2019.

MOTA, Victória de Oliveira. ECONOMIA CIRCULAR: um reaproveitamento sistemático para o desenvolvimento de um novo modelo industrial. Revista Científica Eletrônica Estácio, Ribeirão Preto, v. 10, n. 10, p.188-203, dez. 2017. Semestral. Disponível em: $<$ http://estacioribeirao.com.br/revistacientifica/arquivos/revista10/16.pdf $>$. Acesso em: 10 set. 2019.

PEREIRA, Susana Carla Farias. Rumo à Economia Circular: Sinergia Existente entre as Definições Conceituais Correlatas e Apropriação para a Literatura Brasileira. Recadm: Revista Eletrônica de Ciência Administrativa, Curitiba, v. 1, n. 18, p.35-62, mar. 2019. Trimestral. Disponível em:

$<$ http://www.periodicosibepes.org.br/index.php/recadm/article/view/2581>. Acesso em: 10 set. 2019.

STAHEL, W. R. Circular economy. Nature. V. 531, p. 435-438, 2016. 